RESEARCH ARTICLE

\title{
Gas Saturated Sandstone Reservoir Modeling Using Bayesian Stochastic Seismic Inversion
}

\author{
Rahmat Catur Wibowo ${ }^{1, *}$, Ditha Arlinsky Ar $^{1}$, Suci Ariska ${ }^{1}$, Muhammad Budisatya \\ Wiranatanagara ${ }^{2}$, Pradityo Riyadi ${ }^{2}$ \\ ${ }^{I}$ Geophysical Engineering Department, Engineering Faculty, Universitas Lampung, Lampung, Indonesia \\ ${ }^{2}$ Lemigas $R \&$ D Centre for Oil and Gas Technology, Jakarta Selatan, Indonesia
}

* Corresponding author : rahmat.caturwibowo@eng.unila.ac.id

Tel.:081-327-507517; fax: 0281-638793

Received: Jan 1, 2020, Accepted: March 10, 2020

DOI: 10.25299/jgeet.2020.5.1.4503

\begin{abstract}
This study has been done to map the distribution of gas saturated sandstone reservoir by using stochastic seismic inversion in the "X" field Bonaparte basin. Bayesian stochastic inversion seismic method is an inversion method that utilizes the principle of geostatistics so that later it will get a better subsurface picture with high resolution. The stages in conducting this stochastic inversion technique are as follows, (i) sensitivity analysis, (ii) well to seismic tie, (iii) picking horizon, (iv) picking fault, (v) fault modeling, (vi) pillar gridding, ( vii) making time structure maps, (viii) scale up well logs, (ix) trend modeling, (x) variogram analysis, (xi) stochastic seismic inversion (SSI). In the process of well to seismic tie, statistical wavelets are used because they can produce good correlation values. Then, the stochastic seismic inversion results show that the reservoir in the study area is a reservoir with tight sandstone lithology which has a low porosity value and a value of High acoustic impedance ranging from 30,000 to $40,000 \mathrm{ft} / \mathrm{s} * \mathrm{~g} / \mathrm{cc}$
\end{abstract}

Keywords: seismic, geostatistic, stochastic inversion, Bonaparte basin

\section{Introduction}

The Bonaparte Basin is mostly located off the coast of the Arafura Sea and has an area of about 270,000 km2. This basin is known as one of the basins that produces hydrocarbons in Indonesia, especially hydrocarbons in the form of gases and condensates. The Bonaparte Basin is generally dominated by extensional fractures and very few fractures or compressional structures are found. (O'brien et al, 1993).

According to Barber et al (2003), lithological characters based on biostratigraphic data indicate that the depositional pattern in the Bonaparte Basin Plover Formation is dominated by the deposition of braided fluvial types in the south of the study area to the coastal environment which is influenced by waves (wave dominated shoreline) and in the wave dominated shoreline the northern part is formed in a shallow marine environment. The direction of deposition in the braided fluvial environment is relatively northwest-southeast.

In the oil and gas exploration stage, the seismic method is one of the top choice geophysical methods that can provide better subsurface information by utilizing the seismic wave propagation properties. There is a technique commonly used in this seismic method, namely seismic inversion technique.

Seismic inversion is a method that can describe and estimate the physical properties of subsurface in the form of acoustic impedance values by utilizing seismic data as input and well data as control. Well data here has detailed resolution on thin layer thickness. Meanwhile, seismic data is strongly influenced by bandwidth which for thin layer thicknesses under tunning thickness cannot be resolved properly so as to cause high ambiguity problems in conducting inversions. Therefore, to overcome these problems, an inversion technique with a geostatistical approach can be used which will result in high resolution inversion results.
Bayesian stochastic inversion seismic method is an inversion method that uses a geostatistical algorithm to obtain property models that have detailed resolution such as well data.

In this study a mapping of sandstone reservoirs saturated with plover formation gas using stochastic inversion seismic methods in the " $\mathrm{X}$ " field in the Bonaparte Basin.

\section{Methodology}

In this research 3D post-stack time migration seismic data which is equipped with inline in the east-west direction totaling 300 lines $(1100$ - 1400) and xline in the north-south direction totaling 800 lines $(1000-1800)$ with the distance between the lines which is $18.75 \mathrm{~m}$. Well data used in this study amounted to 4 wells named AR-1, AR-2, AR-3, and AR-4. There are also data markers, namely the top reservoir and base reservoir and checkshot data on each well.

Data processing conducted in this study consisted of qualitative and quantitative data processing for obtaining hydrocarbon prospect zones, log data sensitivity analysis, wavelet extraction, well seismic tie, picking horizon, picking fault, fault modeling, pillar gridding, time-map mapping structure map and depth structure map, isopatch map creation, AI scale-up log and trend modeling so that later stochastic inversion results will be obtained.

Stochastic seismic inversion is an inversion technique whose basic principle uses a random simulation algorithm and produces more than one acoustic impedance model that fills observational seismic data. More than one solution can overcome the problem of non-uniqueness and uncertainty in deterministic inversion, especially in the case of thin films. Another advantage is that this method does not depend on the bandwidth of the seismic data used, but on the block size when simulating the impedance model so that the results of this 
stochastic inversion are less smooth than the deterministic inversion results.

The basic principle of this stochastic seismic inversion is the Bayesian principle. This principle uses the concept of probability which is interpreted as "a measure of a state of knowledge". This principle is a probability principle, where there is a prior probability model, which is then formulated with a likelihood probability function so as to obtain the output of the posterior probability model. This output model is the realization of the impedance model. The formulation of the Bayesian principle is as follows (H. Anders, 1998).

$\sigma(\mathrm{m})=\mathrm{k} . \rho(\mathrm{m}) \cdot \mathrm{L}(\mathrm{m})$

Where:

$\begin{array}{ll}\sigma(\mathrm{m}) & : \text { posterior model } \\ \rho(\mathrm{m}) & : \text { prior } \mathrm{L}(\mathrm{m}) \text { model } \\ \mathrm{L}(\mathrm{m}) & : \text { likelihood function } \\ \mathrm{k} & : \text { constant }\end{array}$

Bayes' theorem is the result of a combination of probability theory and conditional probability. Probability theory states the likelihood of an event occurring with real numbers 0 to 1 . Meanwhile, conditional probability is an event A that occurs when it is known that event B has already occurred (Wapole, 2000).

\section{Result and Discussion}

\subsection{Qualitative Analysis}

In this study four data wells were used, namely AR-1 well, AR-2 well, AR-3 well, and AR-4 well. Qualitative analysis is the first step in determining the hydrocarbon prospect zone. This qualitative analysis is performed by the quick look method where by looking at the response from the gamma ray log, resistivity log, neutron porosity log, and density log. This quick look method aims to interpret zones that are permeable, impermeable, lithological types, and hydrocarbon fluid content.

In the AR-1 well contained in Figure 1 it can be seen that the depth of the reservoir layer containing hydrocarbons is 3955 $\mathrm{ft}$ to $4275 \mathrm{ft}$ which is marked with a dark blue box. In this layer it is known that the response of the gamma ray log curve shows a low response which ranges from 10 gAPI to 60 gAPI so that the layer can be said to be a permeable layer and has a sandstone or sandstone lithology type. Then, the resistivity log curve response, the $\log$ LLD, shows a very high response of more than $80 \mathrm{ohms}$. So the layer can be said to have a gas hydrocarbon fluid content. In addition, the separation of the log density and neutron porosity $\log$ also indicates that the layer is a hydrocarbon prospect zone.

Table 1. Well Data used in the study

\begin{tabular}{|c|c|c|c|c|c|}
\hline & \multirow[b]{2}{*}{ Well Data } & \multicolumn{4}{|c|}{ Well Name } \\
\hline & & AR-1 & AR-2 & $\begin{array}{c}\text { AR- } \\
3\end{array}$ & $\begin{array}{c}\text { AR- } \\
4\end{array}$ \\
\hline 1 & P-Wave & $\mathrm{v}$ & $\mathrm{v}$ & $\mathrm{V}$ & $\mathrm{v}$ \\
\hline 2 & Gamma Ray & $\mathrm{v}$ & $\mathrm{v}$ & $\mathrm{v}$ & $\mathrm{v}$ \\
\hline 3 & Resistivity(LLD) & $\mathrm{v}$ & $\mathrm{v}$ & $\mathrm{v}$ & $\mathrm{v}$ \\
\hline 4 & Neutron Porosity & $\mathrm{v}$ & $\mathrm{v}$ & $\mathrm{v}$ & $\mathrm{v}$ \\
\hline 5 & Density (RHOB) & $\mathrm{v}$ & $\mathrm{v}$ & $\mathrm{v}$ & $\mathrm{v}$ \\
\hline 6 & PHIE & $\mathrm{v}$ & $\mathrm{v}$ & $\mathrm{v}$ & $\mathrm{v}$ \\
\hline
\end{tabular}

Furthermore, the AR-2 well did not show any reservoir layers containing hydrocarbons. This is because in AR-2 well there is no separation between log density and log neutron porosity and is also dominated by high gamma ray log response. In addition, if seen from the response of the log resistivity curve, there is no contrast of high resistivity values. The qualitative analysis on AR-2 wells can be seen in Figure 2.

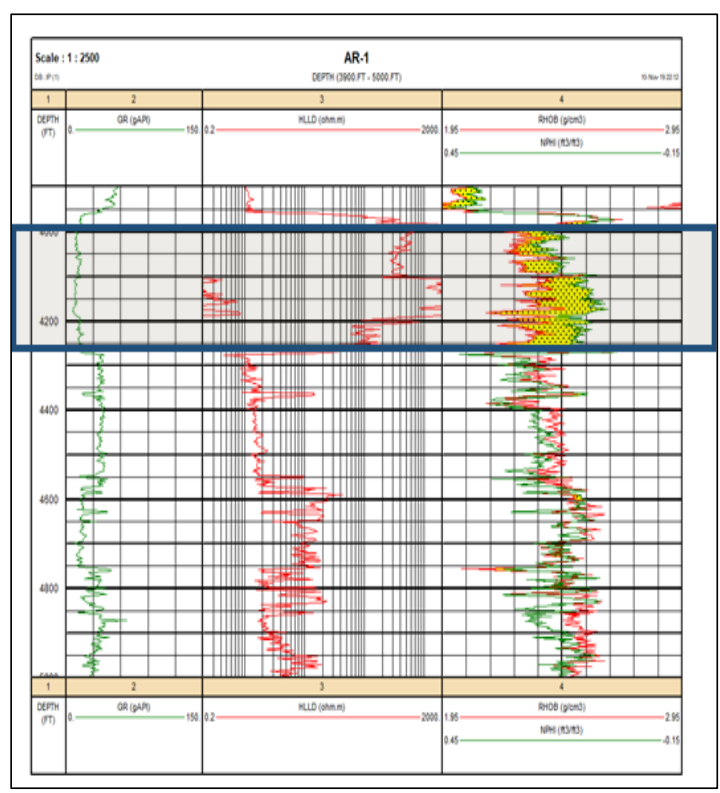

Fig 1. Qualitative analysis of AR-1 wells

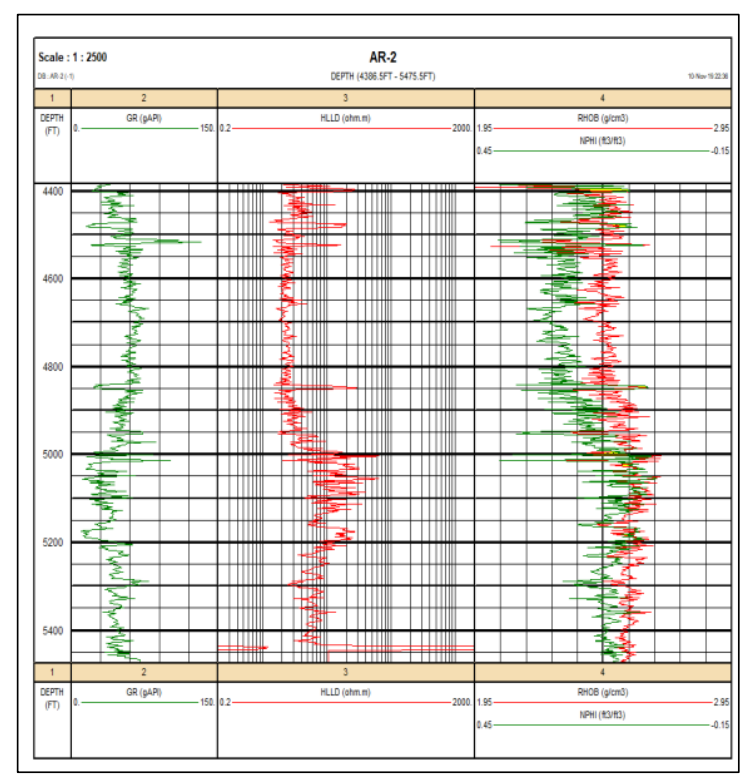

Fig 2. Qualitative analysis of AR-2 wells

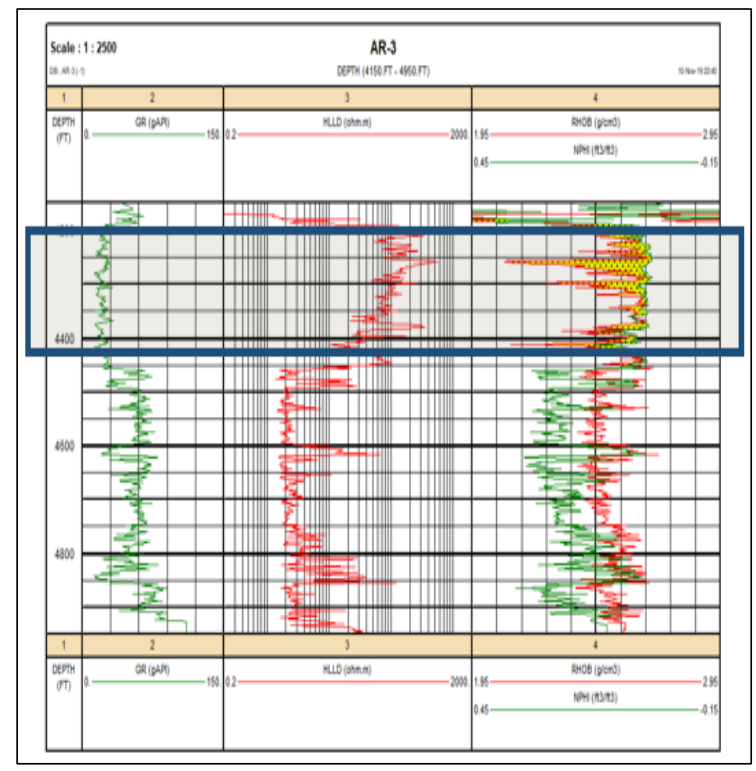

Fig 3. Qualitative analysis of AR-3 wells 
Then, in the AR-3 well contained in Figure 3 it can be seen that the depth of the reservoir layer containing hydrocarbons is $4185 \mathrm{ft}$ to $4492 \mathrm{ft}$ which is marked with a dark blue box. In this layer it is known that the response of the gamma ray log curve shows a low response which ranges from 10 gAPI to 60 gAPI so that the layer can be said to be a permeable layer and has a sandstone or sandstone lithology type. Then, the resistivity log curve response, the log LLD, shows a high response of more than $80 \mathrm{ohms}$. So that the layer can be said to have a gas hydrocarbon fluid content. In addition, the separation of the log density and neutron porosity log also indicates that the layer is a hydrocarbon prospect zone.

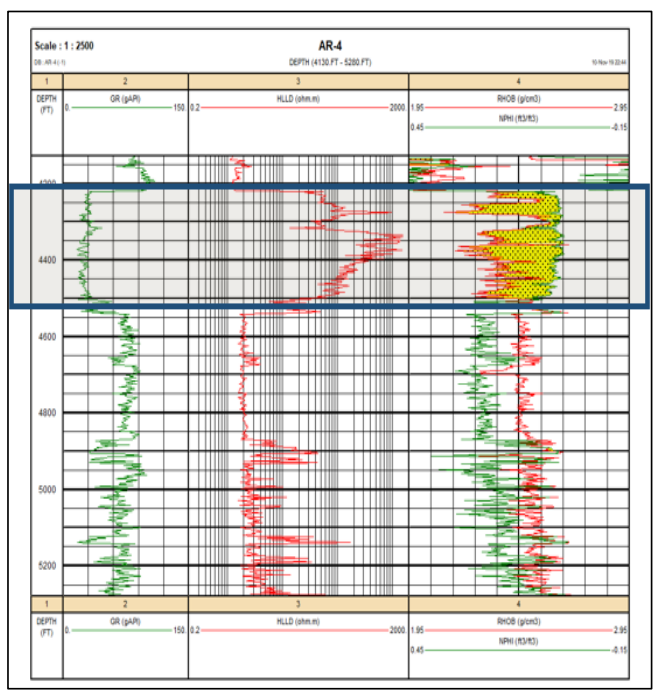

Fig 4. Qualitative analysis of AR-4 wells

Then, in the AR- 4 well contained in Figure 4 it can be seen that the depth of the reservoir layer containing hydrocarbons is $4220 \mathrm{ft}$ to $4541 \mathrm{ft}$ marked with a dark blue box. In this layer it is known that the response of the gamma ray log curve shows a low response which ranges from 10 gAPI to 60 gAPI so that the layer can be said to be a permeable layer and has a sandstone or sandstone lithology type. Then, the resistivity log curve response, the log LLD, shows a high response of more than 80 ohms. So that the layer can be said to have a gas hydrocarbon fluid content. In addition, the separation of the log density and neutron porosity $\log$ also indicates that the layer is a hydrocarbon prospect zone.

\subsection{Sensitivity Analysis}

In the sensitivity analysis in the research, a cross-plot between the P-Impedance and log porosity (PHIT) logs is used with a color scale of values in the form of a gamma ray log. This is done to see the sensitivity of these parameters in separating shale and sand lithology. In this research, sensitivity analysis is divided into two zones, namely the zone marked in yellow is identified as sandstone lithology or sandstone while the zone marked in blue is identified as shale lithology.

Based on the results of cross plots on each well it can be seen that the separation of lithologybetween sandstone (sandstone) and shale is considered sensitive because it can separate the boundary between sand and shale contained in the reservoir zone. Lithology of sandstone or sandstone is indicated by an acoustic impedance value of $27.500 \mathrm{ft} / \mathrm{s} * / \mathrm{cc}$ to 50.000 $\mathrm{ft} / \mathrm{s} * \mathrm{~g} / \mathrm{cc}$ where this is also indicated by a low gamma ray log value and a low porosity value caused by the study area consisting the reservoir with lithology in the form of tight sand. Meanwhile, shale lithology is indicated by acoustic impedance values of $17.000 \mathrm{ft} / \mathrm{s} * \mathrm{~g} / \mathrm{cc}$ to $25.000 \mathrm{ft} / \mathrm{s} * \mathrm{~g} / \mathrm{cc}$ where this is also indicated by high gamma ray log values and relatively high porosity values as well.

\subsection{Time Structure Map}

Time structure map making is done to see trends in the research area which will be used in making trend models or trend modeling in the stochastic inversion process. Time structure map is obtained from the results of picking top reservoir and base reservoir so that it produces a map of the depth of the reservoir zone in the time domain.

Based on the results of the time structure map on the top reservoir and base reservoir, it is known that the area marked in red has shallow depth or the highest elevation area. Meanwhile, the blue area has a fairly deep depth. On the structure map the top reservoir time is known to have a dominant time range of $1100 \mathrm{~ms}$ to $-2100 \mathrm{~ms}$. Meanwhile, the base reservoir time structure map is known to have a range of $-1200 \mathrm{~ms}$ to -2100 ms.

From the two time structure maps above, it can be identified that the location of the four wells ison the anticline peak and it can be identified that the hydrocarbons in the study area migrated from the southeast to the northwest. This is indicated by the contour that represents the lowlands in the southeast and contours that represent the height in the northwest.

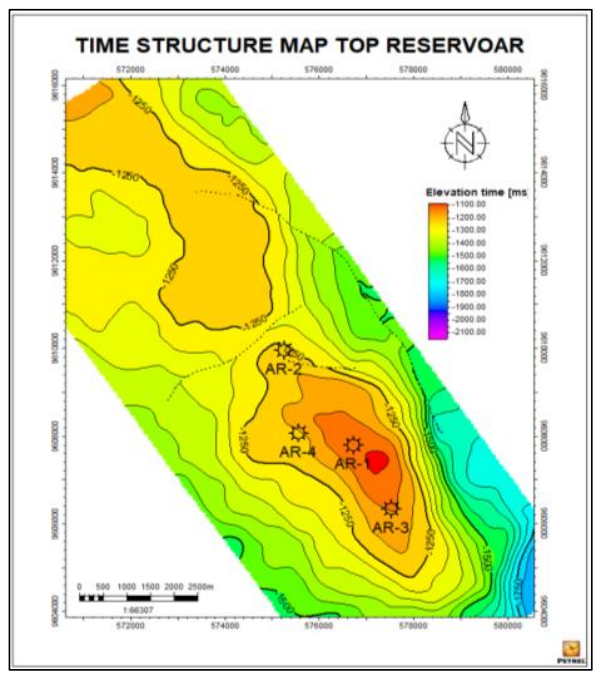

Fig 6. Time Structure Map Top Reservoir

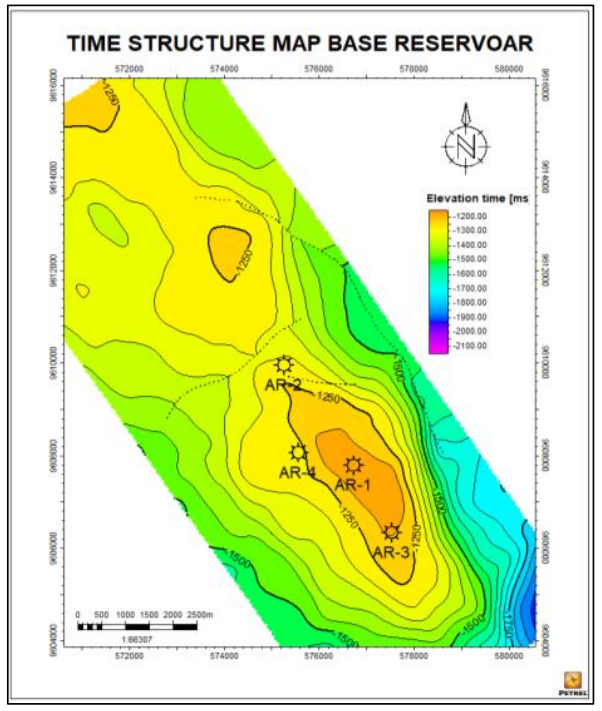

Fig 7. Time Structure Map Base Reservoir

\subsection{Upscaling}

Based on the results of acoustic impedance log scale up that has been done on AR-1 wells, AR-2 wells, AR-3 wells, and AR- 
4 wells it is known thatthere are similarities from the acoustic impedance $\log$ data with the acoustic impedance log data that has been done upscaling. This is evident from the results of the histogram that shows similarities to each other so that it can be said that the upscaling process is correct. The acoustic impedance scale up log process is useful to assist in spreading the acoustic impedance values during a stochastic inversion process.

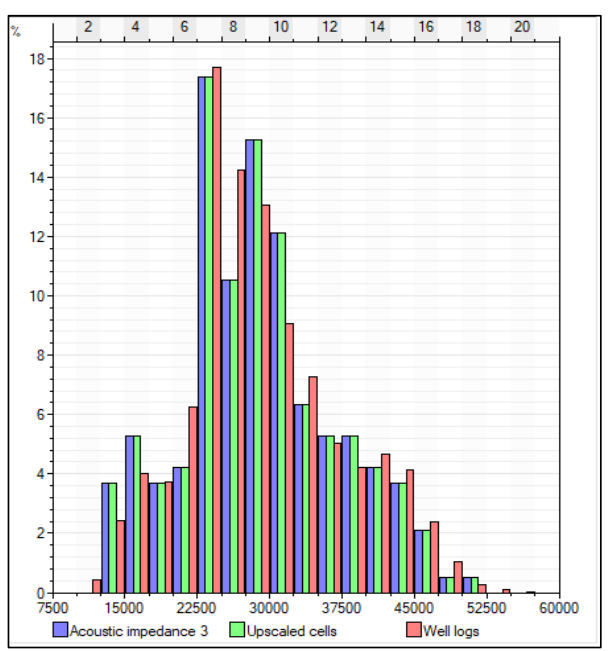

Fig 8. Histogram analysis scale up the acoustic impedance log

\subsection{Trend Modeling}

Making trend modeling is done by using input in the form of acoustic impedance scale up log data and time structure map. The making of this trend model is done to describe the spatial distribution based on the value of the acoustic impedance scale up $\log$ with the trend direction based on the time structure map. The results of the modeling trend are shown in Figure 9.

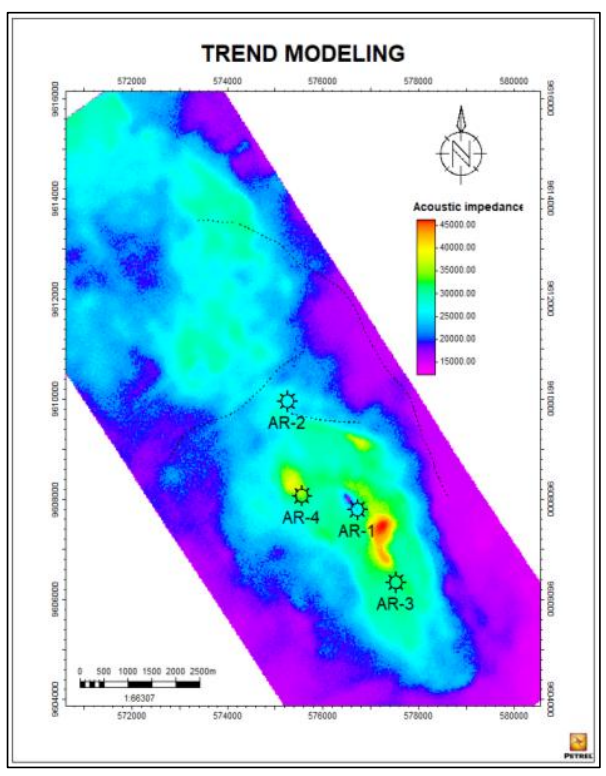

Fig 9. Trend Modeling

Based on the results of the trend modeling conducted, it is known that the acoustic impedance value in the study area has a range of values of $10,000 \mathrm{ft} / \mathrm{s} * \mathrm{~g} / \mathrm{cc}$ to $50,000 \mathrm{ft} / \mathrm{s} * \mathrm{~g} / \mathrm{cc}$ where the high acoustic impedance values are marked with red to green in around the AR-3 well and AR-4 well area, while the low acoustic impedance values are marked in purple to blue around the AR-1 well and AR-2 well area.
In this study, stochastic inversion was carried out using the Bayesian method approach with a total of 20. Meanwhile, the variogram used was the cubic model. In doing this stochastic inversion seismic method is done by using input in the form of acoustic impedance scale up log data and trend models. The results of this stochastic inversion are in Figure 10.

Based on the acoustic impedance distribution map using stochastic seismic inversion it is known that the area marked in red is an area that has a high acoustic impedance value with a range of values of $30,000 \mathrm{ft} / \mathrm{s} * \mathrm{~g} / \mathrm{cc}$ to $40,000 \mathrm{ft} / \mathrm{s} * \mathrm{~g} / \mathrm{cc}$ and is identified as reservoir with lithology in the form of tight sand saturated with hydrocarbons in the form of gas which is also supported by the results of interpretation of data wells that have been carried out in the previous process on AR-1 wells, AR-3 wells, and AR-4 wells that are identified as having a gaseous hydridarbon content.

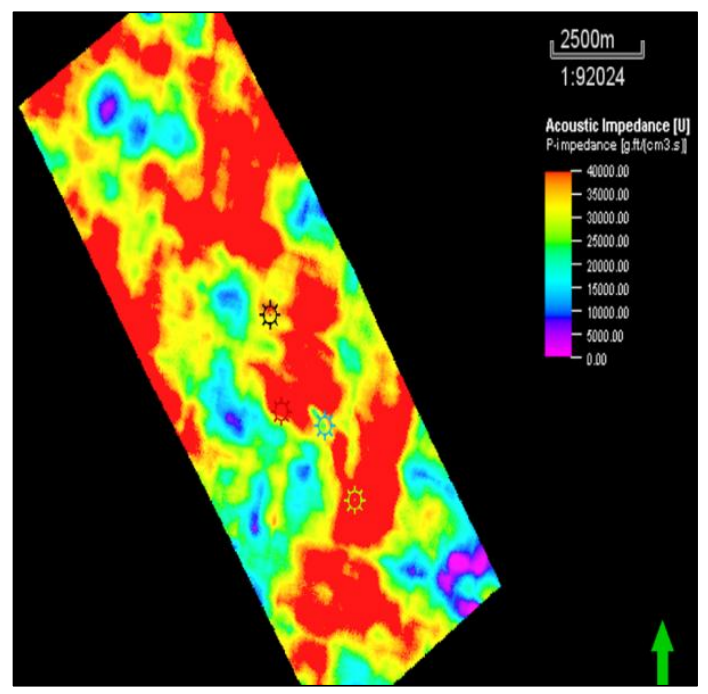

Fig10. Map of acoustic impedance acoustic impedance distribution

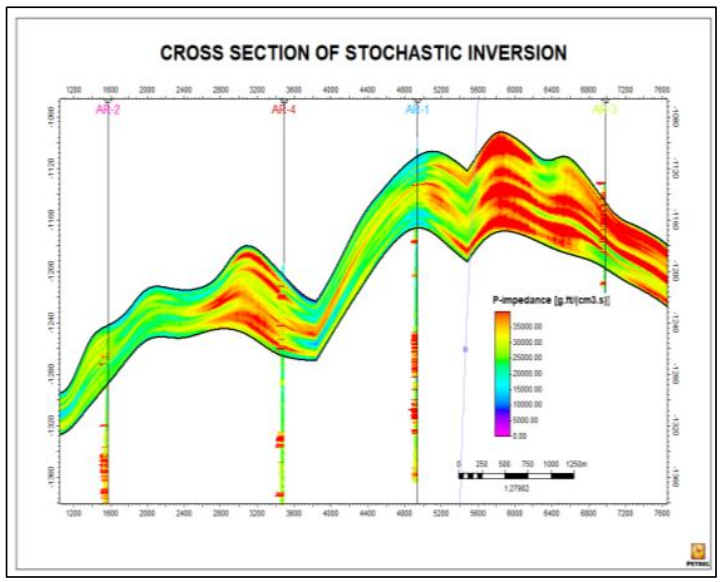

Fig11. Cross-section of stochastic seismic inversion results

\subsection{Depth Structure Map}

Depth structure map is obtained from the conversion of time structure map into depth domain. In doing time to depth conversion the stacking velocity method is used which is a method that can convert from time domain to depth domain using the speed model. Making this depth structure map is very important because there are differences between the two domains that can cause ambiguity when interpreted where in fact conditions are domain depth, but seismic data has a time domain (TWT).

\subsection{Stochastic Inversion}




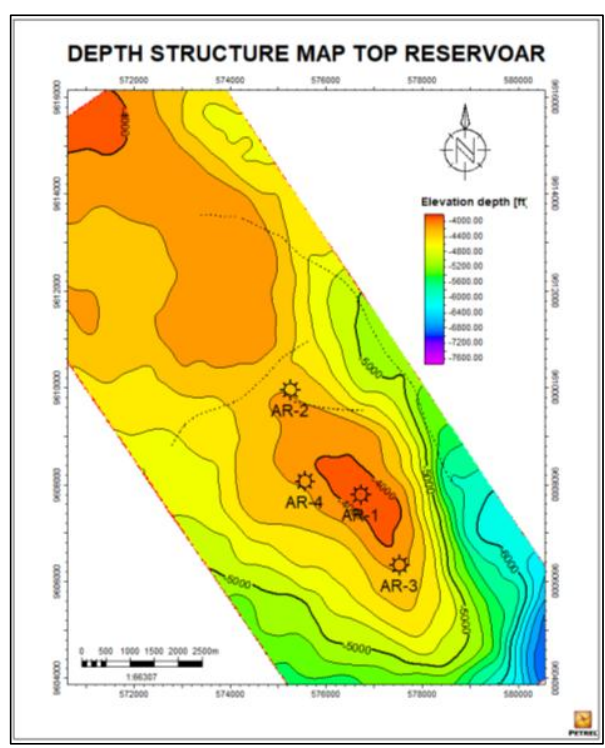

Fig 12. Depth Structure Map Top Reservoir

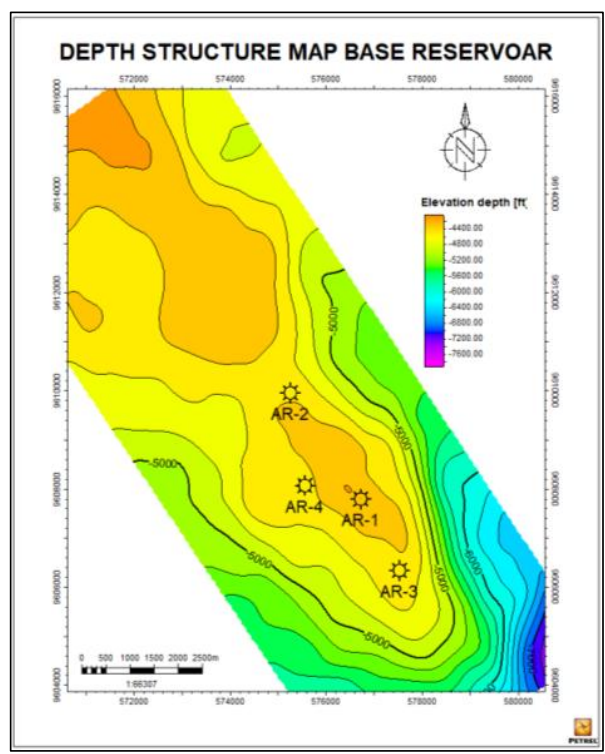

Fig13. Depth Structure Map Base Reservoir

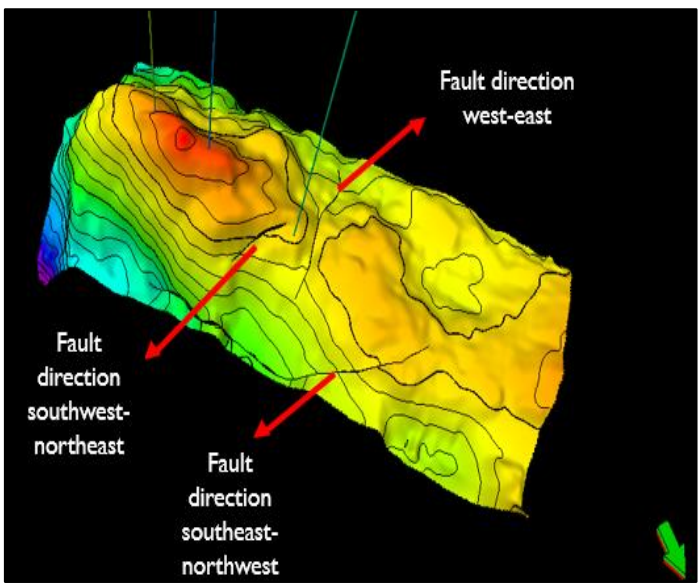

Fig14. 3D map of the structure of the top reservoir depth

Based on the map of the depth structure of the top reservoir and base reservoir it is known that the prospect area of the four wells is identified to be in the height area in the southeast where it has a depth of $4000 \mathrm{ft}$ to $4500 \mathrm{ft}$. In the prospect area there are two areas of height in the form of anticline which are in the southeast and northwest. This structure was formed because there is a fault that separates the two height areas. In the research area, there are three main faults namely faults that are southwest-northeast, faults that are east-west, and faults that are southeast-northwest where these three faults are identified as normal faults or normal faults. These faults can act as structural traps where hydrocarbons will migrate and are trapped in these structural traps so that hydrocarbons can accumulate in them.

\subsection{Isopach Map}

Isopach map making is done to describe the thickness of the reservoir layer where this map is made by subtracting the depth of the top reservoir from the base reservoir. Based on the isopatch map that has been made it is known that in AR-1 wells, AR-3 wells, and AR-4 wells have a thick reservoir layer which is around $300 \mathrm{ft}$ to $450 \mathrm{ft}$. Meanwhile, the AR-2 well has a thinner reservoir layer which is around $210 \mathrm{ft}$. On the isopach map found in Figure 14 it can be said that there was a depletion of the reservoir from the southeast to the northwest.

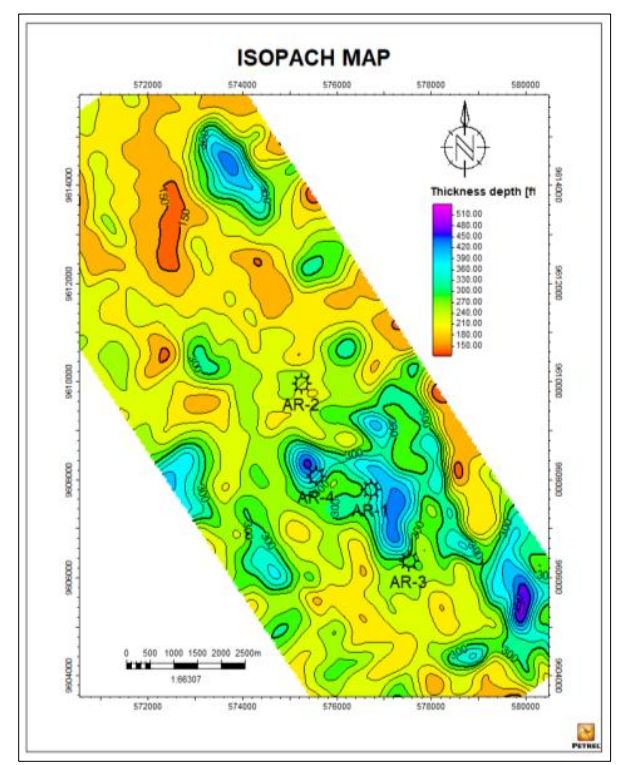

Fig 15. Isopach Map

\section{Conclusion}

This study showed that the Bayesian stochastic inversion can produce better results than the deterministic inversion. Because of the smoothness and average, the deterministic inversion was unsuitable for constraining reservoir models when this model was used for volumetric calculations, estimation of connectivity, and individualization of sand bodies or fluid flow simulation

Based on the results, it is known that the hydrocarbon prospect zone has a high acoustic impedance value ranging from $30,000 \mathrm{ft} / \mathrm{s} * \mathrm{~g} / \mathrm{cc}$ to $40,000 \mathrm{ft} / \mathrm{s} * \mathrm{~g} / \mathrm{cc}$ which is at a depth of $4,000 \mathrm{ft}$ to $4,500 \mathrm{ft}$. This is due to the reservoir of the study area which is dominated by tight sandstone lithology which contains gas and has a low porosity value.

Finally, the Bayesian stochastic inversion efficiently improved the reservoir characterization process by not only producing accurate estimation of the low-scale reservoir heterogeneities but also generating outcomes that help study the uncertainty analysis.

\section{References}

Natasia, N., Syafri, I., Alfadli, M.K., Arfiansyah, K., 2016. Stratigraphy Seismic and sedimentation Development of Middle Baong Sand, Aru Field, North Sumatera Basin. J. Geoscience, Engineering, Environment, and 
Technology 1, 51-58.

Anderson, F. dan Gray, D. 2001. Using LMR for Dual Attribute Lithology Identification. SEG Expanded Abstracts. Veritas DGC Inc. San Antonio.

Bohling, G. 2005. Introduction to Geostatistics and Variogram Analysis. Kansas Geological Survey. Kansas.

Cooke, D., and Cant, J., 2010, Model-based Seismic Inversion: Comparing deterministic and probabilistic approaches: Canadian, Society of Exploration Geophysicist Recorder, 35, 28-39.

Dewanto, O. 2009. Well Logging. Universitas Lampung. Lampung.

Dewanto, O., Mulyatno, B.S., Rustadi and Wibowo, R.C. 2017. Determining the Temperature of Shale Material Conversion Into Crude Oil Based on Organic Clay and Organic Carbonate Test Outside Reservoar. International Journal of Mechanical and Mechatronics Engineering, IJMME. Vol. 17, No.05. ISSN: 2077-124X (Online), p. 84-89.

Dorsel, D., dan Breche, L.T. 1997. Kriging, Environmental Sampling and Monitoring Primer. John Wiley and Sons. Virginia.

Doveton, H. 1986. Log Analysis of Subsurface Geology Concepts and Computer Methods. John Wiley and Sons. Virginia.

Francis, A., 2006a, Understanding stochastic inversion: part 1 First Break 24 69-77.

Francis, A., 2006b, Understanding stochastic inversion: part 2 First Break 24 79-84.

Harsono, A. 1997. Evaluasi Formasi dan Aplikasi Log. Schlumberger Oilfield Services. Jakarta.

Isaaks, E., dan Srivastava, R.M. 1989. An Introduction to Applied Geostatistics. Oxford University Press.

Koesoemadinata. 1978. Geologi Minyak dan Gas Bumi. Institut Teknologi Bandung. Bandung.

Lattimer, R., Bahret, S., Sullivan, S., Horine, R., Mills, W., Sturrock, V. 1999. Reservoar Characterization using Geostatistical Inversion for the Amberjack Field, offshore Gulf of Mexico. SEG Journal. Houston.

Mulyatno, B.S., Dewanto, O., Rizky, S. 2018. Determining Layer Oil Shale as New Alternatve Energy Sources
Using Core Analysis and Well Log Method. International Journal of Engineering and Technology, IJET. Vol. 7, No. 04.36 ISSN: 2227-524X (Online), p. 941-949.

Rider, M. 1996. The Geological Interpretation of Well Logs. Caithness, Scotland.

Rob, S., dan Mike, B. 2014. Seismic Amplitude an interpreter's handbook. Cambridge university press.

Russell, B. H. 1991. Introduction to Seismic Inversion Methods, S.N. Domenico. Editor Course Notes Series, Volume 2nd edition.

Schabenberger, O., Gotwey, C. A. 2005. Statistical Methods for Spatial Data Analysis. Chapman \& Hall/CRC. USA.

Schlumberger. 1989. Log Interpretation Principles/Aplication. Schlumberger Educational Services. Texas.

Siallagan, F., Dewanto O., dan Mulyatno, B.S. 2019. Analisis Reservoar Migas berdasarkan Parameter Petrofisika dari 7 Sumur di Cekungan Sumatera Selatan. Jurnal Geofisika Eksplorasi. Vol. 3, No. 2.

Srivastava R P and Sen M K, 2009, Fractal-based stochastic inversion of poststack seismic data using very fast simulated annealing, J. Geophys. Eng, 6, p.412.

Srivastava R P and Sen M K, 2010, Stochastic inversion of prestack seismic data using fractal-based initial models, Geophysics, 75, p.47-59.

Stefan, M., 1999, Variogram analysis of magnetic and gravity data, Geophysics, 64, no. 3, 776-784.

Telford, W. M., Geldart, L. P., dan Sheriff, R. E. 1990. Applied Geophysics - Second Edition. Cambridge University Press. USA

Torres-Verdin C, Victoria M, Merletti G and Pendrel J., 1999, Trace-based and geostatistical inversion of 3-D seismic data for thin-sand delineation: an application in San Jorge Basin, Argentina The Leading Edge 18 1070-7.

Webster, R., dan Oliver, M.A. 2007. Geostatistics for Environmental Scientiests Second Edition. John Wiley \& Sons Ltd. Inggris.

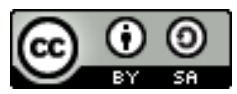

(C) 2020 Journal of Geoscience, Engineering, Environment and Technology. All rights reserved. This is an open access article distributed under the terms of the CC BY-SA License (http://creativecommons.org/licenses/by-sa/4.0/) 